Pacific Journal of Mathematics

NEW CHARACTERIZATION OF CHARACTERISTIC
FUNCTIONS OF ABSOLUTELY CONTINUOUS 


\title{
A NEW CHARACTERIZATION OF CHARACTERISTIC FUNCTIONS OF ABSOLUTELY CONTINUOUS DISTRIBUTIONS
}

\author{
Simeon M. Berman
}

It is well known that if $g$ belongs to $L_{2}$, then

$$
\frac{\int g(x) \bar{g}(x+y) d x}{\int|g(x)|^{2} d x}
$$

is the characteristic function of an absolutely continuous distribution function. Conversely, every such characteristic function has the representation given above. Here we shown that if $R(s, t)$ is a covariance function such that $R(s, s)$ belongs to $L_{1}$, then

$$
\frac{\int R(s, s+t) d s}{\int R(s, s) d s}
$$

is the characteristic function of an absolutely continuous distribution. Conversely, every such characteristic function has the latter representation (put $R(s, t)=g(s) \bar{g}(t)$ ). The use of this new result is that certain functions are directly seen to be of the second form but not the first; hence, they can be identified as characteristic functions of absolutely continuous distributions.

1. The main theorem. Let $R(s, t),-\infty<s, t<\infty$, be a complex-valued Borel function of two variables. It is a covariance function if for any positive integer $n$, and any set of pairs $\left(s_{i}, u_{i}\right)$, $i=1, \cdots, n$,

$$
\sum_{i=1}^{n} \sum_{j=1}^{n} R\left(s_{i}, s_{j}\right) u_{i} u_{j} \geqq 0
$$

By Kolmogorov's existence theorem and the well known moment properties of Gaussian processes, for every covariance function there exists a probability space and a complex Gaussian process $X(t)$, $-\infty<t<\infty$, on the space such that

$$
E X(t)=0 \text { for all } t, \quad E X(s) \bar{X}(t)=R(s, t) \text { for all } s, t .
$$

We say that $X$ is associated with $R$. 
The function $R(s, s)$ is nonnegative because it is equal to $E|X(s)|^{2}$. If

$$
\int_{-\infty}^{\infty} R(s, s) d s<\infty
$$

then there exists an associated process $X$ which is measurable and satisfies

$$
E \int_{-\infty}^{\infty}|X(s)|^{2} d s=\int_{-\infty}^{\infty} E|X(s)|^{2} d s<\infty
$$

It also follows that $X(t)$ belongs to $L_{2}$ almost surely, and so there is a measurable version of the Fourier transform process

$$
\hat{X}(u)=\int_{-\infty}^{\infty} e^{i u s} X(s) d s,-\infty<u<\infty
$$

By Parseval's Theorem we also have

$$
\int_{-\infty}^{\infty} E|X(s)|^{2} d s=\frac{1}{2 \pi} \int_{-\infty}^{\infty} E|\hat{X}(u)|^{2} d u
$$

THEOREM 1. Let $R$ be a covariance function satisfying (1.1). Then the function

$$
r(t)=\frac{\int_{-\infty}^{\infty} R(s, s+t) d s}{\int_{-\infty}^{\infty} R(s, s) d s}
$$

is a characteristic function. The corresponding distribution function is absolutely continuous with the derivative

$$
g(u)=\frac{E|\hat{X}(-u)|^{2}}{\int_{-\infty}^{\infty} E|\hat{X}(y)|^{2} d y}
$$

where $X$ is the associated process satisfying (1.2). Conversely if $r(t)$ is the characteristic function of an absolutely continuous distribution, then there exists $R$ satisfying (1.1) such that $r$ is representable as (1.5).

Proof. First we prove the direct assertion. It follows from the definition of $X$ that 


$$
\int_{-\infty}^{\infty} R(s, s+t) d s=\int_{-\infty}^{\infty} E X(s) \bar{X}(s+t) d s .
$$

By virtue of condition (1.1) and the Cauchy-Schwarz inequality, we can take the expectation outside of the integral, and then apply the Parseval theorem:

$$
E \int_{-\infty}^{\infty} X(s) \bar{X}(s+t) d s=E\left\{(1 / 2 \pi) \int_{-\infty}^{\infty} e^{-i u t}|\hat{X}(u)|^{2} d u\right\}
$$

It follows that the ratio in (1.5) is equal to

$$
\frac{\int_{-\infty}^{\infty} e^{i u t} E|\hat{X}(-u)|^{2} d u}{\int_{-\infty}^{\infty} E|\hat{X}(y)|^{2} d y}
$$

This is exactly the Fourier transform of the function $g(u)$ in (1.6).

The converse is simple: it is given in the above abstract.

2. Factorable covariances. $R$ is said to be factorable if there exists a monotone function $A(y)$ and a "kernel" function $\phi(t, y)$ such that

$$
R(s, t)=\int_{-\infty}^{\infty} \phi(s, y) \bar{\phi}(t, y) d A(y)
$$

The condition (1.1) becomes

$$
\int_{-\infty}^{\infty} \int_{-\infty}^{\infty}|\phi(s, y)|^{2} d A(y) d s<\infty
$$

It follows (by Fubini's theorem) that $\phi(\cdot, y)$ belongs to $L_{2}$ for almost all $y$ (with repect to $d A$ ); thus

$$
\hat{\phi}(u, y)=\int_{-\infty}^{\infty} e^{i u z} \phi(z, y) d z
$$

exists for all such $y$. By virtue of the isometry $X(t) \rightarrow \phi(t, \cdot)$ the density (1.6) takes the form

$$
g(u)=\frac{\int_{-\infty}^{\infty}|\hat{\phi}(-u, y)|^{2} d A(y)}{\int_{-\infty}^{\infty} \int_{-\infty}^{\infty}|\hat{\phi}(u, y)|^{2} d u d A(y)} .
$$


As a characteristic function $r(t)$ is also the covariance function of a stationary Gaussian process. When the spectral distribution is absolutely continuous, the process has a well known representation as a moving average of "white noise" on the line (see [2], p. 533). We will show that when $R$ is factorable the stationary process with covariance of the form (1.5) also has a representation as a moving average of "noise" in the plane. The latter representation is more informative and easiler to derive in certain special cases (see $\$ 4$ below).

Let $W$ be a real Gaussian random set function defined over the plane Borel sets, that is, $W(C)$ has a normal distribution for every plane Borel set $C$. Let $W$ have the following moment structure:

$E W(C)=0$ for all $C$

$E W(C) W\left(C^{\prime}\right)=0$ if $C$ and $C^{\prime}$ are disjoint (independent increments) sets.

$E W^{2}(C)=\int_{B} d x \cdot \int_{B^{\prime}} d A(y)$ if $C=B \times B^{\prime}$ is a product of two linear

Consider the stochastic integral with respect to $W$, divided by a positive constant:

$$
Y(t)=\frac{\int_{-\infty}^{\infty} \int_{-\infty}^{\infty} \phi(x+t, y) W(d x \times d y)}{\left\{\int_{-\infty}^{\infty} \int_{-\infty}^{\infty}|\phi(x, y)|^{2} d x d A(y)\right\}^{\frac{1}{2}}} .
$$

By a direct calculation and by means of the fundamental properties of the stochastic integral we find that the process $Y(t)$ is stationary (and Gaussian) with covariance function (1.5).

3. Change of time parameter in the covariance. Let $R(s, t)$ be a covariance, and $f(x)$ a real Borel function. Then the composite function $R(f(x), f(y))$ is also a covariance function (in $x$ and $y)$. According to Theorem 1 , if

$$
\int_{-\infty}^{\infty} R(f(x), f(x)) d x<\infty
$$

then

$$
r(t)=\frac{\int_{-\infty}^{\infty} R(f(x), f(x+t)) d x}{\int_{-\infty}^{\infty} R(f(x), f(x)) d x}
$$


is the characteristic function of an absolutely continuous distribution. By means of this result we can identify some general and interesting functions as such characteristic functions.

EXAMPLE. Let $\sigma^{2}(t),-\infty<t<\infty$, be the incremental second moment function of a Gaussian process with mean 0 and stationary increments $\left(\sigma^{2}(t)=E|U(s+t)-U(s)|^{2}\right.$ where $U$ has stationary increments). Then the covariance function of the process is

$$
R(s, t)=\frac{1}{2}\left[\sigma^{2}(s)+\sigma^{2}(t)-\sigma^{2}(t-s)\right] .
$$

Let $f(x)$ be a Borel function such that

$$
\int_{-\infty}^{\infty} \sigma^{2}(f(x)) d x<\infty
$$

then (3.1) is fulfilled, and so

$$
r(t)=1-\frac{\int_{-\infty}^{\infty} \sigma^{2}(f(x+t)-f(x)) d x}{2 \int_{-\infty}^{\infty} \sigma^{2}(f(x)) d x}
$$

is the characteristic function of an absolutely continuous distribution.

Let $f(x)$ be a Borel function such that

$$
\int_{-\infty}^{\infty}|f(x)|^{\alpha} d x=1
$$

for some $\alpha, 0<\alpha \leqq 2$; then

$$
r(t)=1-\frac{1}{2} \int_{-\infty}^{\infty}|f(x+t)-f(x)|^{\alpha} d x
$$

is a characteristic function with an absolutely continuous distribution; indeed, it is a special case of (3.3) with $\sigma^{2}(t)=t^{\alpha}$. (The fact that (3.4) is a characteristic function was first proved by Lawrence Shepp in a private communication.)

This can be used to prove a general result about the space $L_{\alpha}$. According to the classical representation of the characteristic function of an absolutely continuous distribution as a convolution, there exists a function $\tilde{f}$ such that

$$
\int_{-\infty}^{\infty}|\tilde{f}(x)|^{2} d x=1
$$


and $r(t)$ is representable as

$$
1-\frac{1}{2} \int_{-\infty}^{\infty}|\tilde{f}(x+t)-\tilde{f}(x)|^{2} d x
$$

From (3.4) we then conclude that

$$
\int_{-\infty}^{\infty}|f(x+t)-f(x)|^{\alpha} d x=\int_{-\infty}^{\infty}|\tilde{f}(x+t)-\tilde{f}(x)|^{2} d x, \text { for all } t .
$$

As far as $I$ can determine the existence of such an $\tilde{f}$ in $L_{2}$ for each $f$ in $L_{\alpha}$ is a result unknown up to now.

4. A new proof of Polya's theorem and related results. Polya described a class of characteristic functions, now called "Polya characteristic functions". [4] He showed that if $r(t)$ is a convex function such that $r(t) \geqq 0, r(t)=r(-t), r(0)=1$, and $\lim _{t \rightarrow \infty} r(t)=0$, then $r(t)$ is the characteristic function of an absolutely continuous distribution. We will show that such a function is representable as in Theorem 1, and so provide a new proof of Polya's theorem; furthermore, we will get an explicit form of the density from the results of $\$ 2$, and a stochastic integral representation.

As a convex function, $r(t)$ has an integral representation

$$
r(t)=\int_{|t|}^{\infty} f(x) d x
$$

where $f(x), x \geqq 0$, is nonnegative and nonincreasing, and

$$
\int_{0}^{\infty} f(x) d x=1
$$

Indeed, take $f$ as the negative of the right hand derivative of $r$ (see [3], p. 5). Extend $f$ to all $x$ by assigning it the value 0 on the negative axis. Then $r(t)$ is representable as

$$
r(t)=\int_{-\infty}^{\infty} \min (f(x), f(x+t)) d x
$$

This is of the form (1.5) with $R(s, t)=\min (s, t)$. Thus $r$ is a characteristic function of the indicated type.

Let $I(t)$ be the indicator function of the positive $t$-axis. The covariance $\min (s, t)$ is factorable for positive $s$ and $t$ : 


$$
\min (s, t)=\int_{0}^{\infty} I(s-y) I(t-y) d y .
$$

Put $\phi(x, y)=I(f(x)-y)$ and $A(y)=y$ for $y>0$, and $A(y)=0$ for $y \leqq 0$. It follows from (2.1) that the density function of the Polya characteristic function is

$$
(1 / 2 \pi) \int_{0}^{\infty}\left|\int_{-\infty}^{\infty} e^{i u x} I(f(x)-y) d x\right|^{2} d y
$$

The random set function $W$ in (2.2) is the 2-dimensional Brownian motion with independent increments, and the stochastic integral becomes

$$
Y(t)=\iint_{\{y>0\}} I(f(x+t)-y) W(d x \times d y) .
$$

Such a representation for the Polya covariance process was recently given by Cabana and Wschebor [1].

ACKNOWLEDGement. I thank Lawrence Shepp for a valuable observation which led to a significant improvement of this work.

\section{REFERENCES}

1. E. M. Cabana, and M. Wschebor, On the barrier problem for stationary Gaussian processes, Univ. Repub. Fac. Ingen. Agrimens. Montevideo Publ. Mat. Estadist., 4 (1969), 123-128.

2. J. L. Doob, Stochastic Processes, Wiley, New York, 1953.

3. M. A. Krasnoselskii, and Ya. B. Rutickii, Convex Functions and Orlicz Spaces, translated from the first Russian edition by Leo F. Boron, P. Noordhoff, Groningen, 1961.

4. G. Polya, Remark on characteristic functions, Proceedings First Berkeley Symposium Math. Statist. Probability, Edited by J. Neyman, Berkeley, 1949.

Received March 18, 1974. This paper represents results obtained at the Courant Institute of Mathematical Sciences, New York University, under the sponsorship of the National Science Foundation, Grant NSFGP-28651. 



\section{PACIFIC JOURNAL OF MATHEMATICS}

\section{EDITORS}

RICHARD ARENS (Managing Editor)

University of California

Los Angeles, California 90024

\section{J. DugundJI}

Department of Mathematics University of Southern California Los Angeles, California 90007

D. Gilbarg and J. Milgram

Stanford University

Stanford, California 94305

\section{ASSOCIATE EDITORS}
E. F. BECKENBACH
B. H. NeumanN
F. WoLF
K. YoshiDA

\section{SUPPORTING INSTITUTIONS}

\author{
UNIVERSITY OF BRITISH COLUMBIA \\ CALIFORNIA INSTITUTE OF TECHNOLOGY \\ UNIVERSITY OF CALIFORNIA \\ MONTANA STATE UNIVERSITY \\ UNIVERSITY OF NEVADA \\ NEW MEXICO STATE UNIVERSITY \\ OREGON STATE UNIVERSITY \\ UNIVERSITY OF OREGON \\ OSAKA UNIVERSITY
}

\author{
UNIVERSITY OF SOUTHERN CALIFORNIA \\ STANFORD UNIVERSITY \\ UNIVERSITY OF TOKYO \\ UNIVERSITY OF UTAH \\ WASHINGTON STATE UNIVERSITY \\ UNIVERSITY OF WASHINGTON \\ AMERICAN MATHEMATICAL SOCIETY
}

The Supporting Institutions listed above contribute to the cost of publication of this Journal, but they are not owners or publishers and have no responsibility for its contents or policies.

Mathematical papers intended for publication in the Pacific Journal of Mathematics should be in typed form or offset-reproduced (not dittoed), double spaced with large margins. Underline Greek letters in red, German in green, and script in blue. The first paragraph or two must be capable of being used separately as a synopsis of the entire paper. Items of the bibliography should not be cited there unless absolutely necessary, in which case they must be identified by author and Journal, rather than by item number. Manuscripts, in duplicate, may be sent to any one of the four editors. Please classify according to the scheme of Math. Reviews, Index to Vol. 39. All other communications should be addressed to the managing editor, or Elaine Barth, University of California, Los Angeles, California, 90024.

100 reprints are provided free for each article, only if page charges have been substantially paid. Additional copies may be obtained at cost in multiples of 50 .

The Pacific Journal of Mathematics is issued monthly as of January 1966. Regular subscription rate: $\$ 72.00$ a year (6 Vols., 12 issues). Special rate: $\$ 36.00$ a year to individual members of supporting institutions.

Subscriptions, orders for back numbers, and changes of address should be sent to Pacific Journal of Mathematics, 103 Highland Boulevard, Berkeley, California, 94708.

PUBLISHED BY PACIFIC JOURNAL OF MATHEMATICS, A NON-PROFIT CORPORATION Printed at Jerusalem Academic Press, POB 2390, Jerusalem, Israel.

$$
\begin{gathered}
\text { Copyright (C) } 1975 \text { Pacific Journal of Mathematics } \\
\text { All Rights Reserved }
\end{gathered}
$$




\section{Pacific Journal of Mathematics}

\section{Vol. 58, No. $2 \quad$ April, 1975}

Zvi Artstein and John Allen Burns, Integration of compact set-valued functions . . . . . . . . . 297

Mark Benard, Characters and Schur indices of the unitary reflection group $[321]^{3} \ldots \ldots \ldots . .309$

Simeon M. Berman, A new characterization of characteristic functions of absolutely continuous

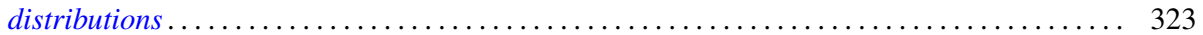

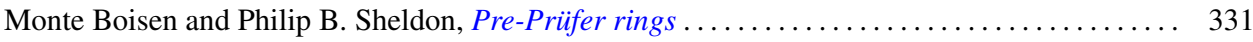

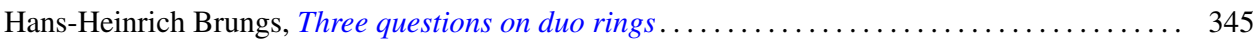

Iracema M. Bund, Birnbaum-Orlicz spaces of functions on groups................. 351

John D. Elwin and Donald R. Short, Branched immersions between 2-manifolds of higher

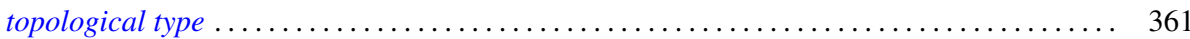

Eric Friedlander, Extension functions for rank 2, torsion free abelian groups . .......... 371

Jon Froemke and Robert Willis Quackenbush, The spectrum of an equational class of

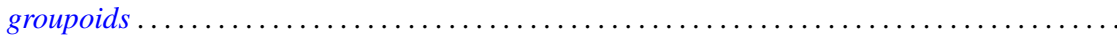

Barry J. Gardner, Radicals of supplementary semilattice sums of associative rings ...........

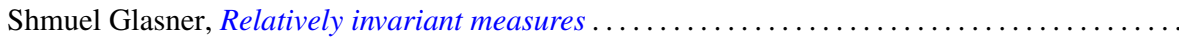

George Rudolph Gordh, Jr. and Sibe Mardesic, Characterizing local connectedness in inverse

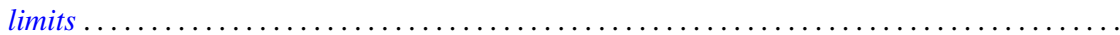

Siegfried Graf, On the existence of strong liftings in second countable topological spaces......

Stanley P. Gudder and D. Strawther, Orthogonally additive and orthogonally increasing

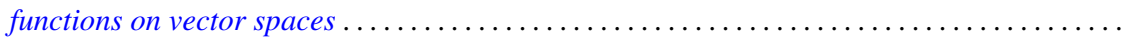

Darald Joe Hartfiel and Carlton James Maxson, A characterization of the maximal monoids and

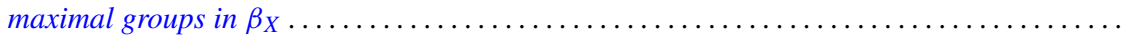

Robert E. Hartwig and S. Brent Morris, The universal flip matrix and the generalized faro-shuffle. .

William Emery Haver, Mappings between ANRs that are fine homotopy equivalences. .

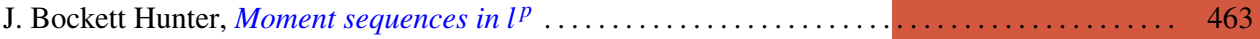

Barbara Jeffcott and William Thomas Spears, Semimodularity in the completion of a poset.... 467

Jerry Alan Johnson, A note on Banach spaces of Lipschitz functions . . . . . . . . . . . . 475

David W. Jonah and Bertram Manuel Schreiber, Transitive affine transformations on

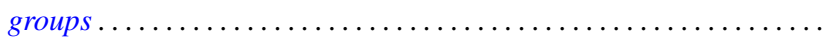

Karsten Juul, Some three-point subset properties connected with Menger's characterization of

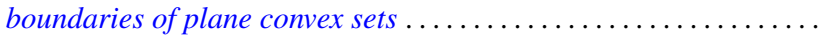

Ronald Brian Kirk, The Haar integral via non-standard analysis . . . . . . . . . . . . . 517

Justin Thomas Lloyd and William Smiley, On the group of permutations with countable

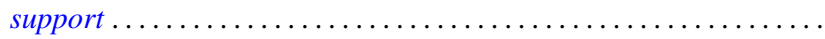

Erwin Lutwak, Dual mixed volumes .................................. 531

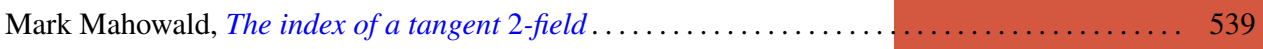

Keith Miller, Logarithmic convexity results for holomorphic semigroups . . . . . . . . . . . . 549

Paul Milnes, Extension of continuous functions on topological semigroups . . . . . . . . . . 553

Kenneth Clayton Pietz, Cauchy transforms and characteristic functions ................ 563

James Ted Rogers Jr., Whitney continua in the hyperspace $C(X) \ldots \ldots \ldots \ldots \ldots \ldots \ldots \ldots .569$

Jean-Marie G. Rolin, The inverse of a continuous additive functional . . . . . . . . . . . . 585

William Henry Ruckle, Absolutely divergent series and isomorphism of subspaces . ........ 605

Rolf Schneider, A measure of convexity for compact sets . ..................... 617

Alan Henry Schoenfeld, Continous measure-preserving maps onto Peano spaces .......... 627

V. Merriline Smith, Strongly superficial elements .......................... 643

Roger P. Ware, A note on quadratic forms over Pythagorean fields . . . . . . . . . . . . . . 651

Roger Allen Wiegand and Sylvia Wiegand, Finitely generated modules over Bezout rings . . . . 655

Martin Ziegler, A counterexample in the theory of definable automorphisms . . . . . . . . . 665 